\title{
Association between omentin-1 expression in human epicardial adipose tissue and coronary atherosclerosis
}

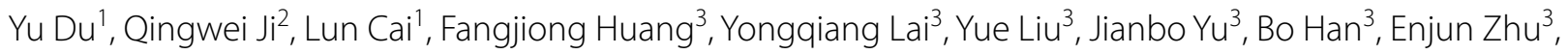
Jinwei Zhang ${ }^{3}$, Yujie Zhou ${ }^{1,2}$, Zhijian Wang ${ }^{2^{*+}}$ and Yingxin Zhao ${ }^{1,2^{*}+}$

\begin{abstract}
Background: Omentin-1, a novel adipocytokine mainly expressed in visceral adipose tissue, has been found to inhibit the inflammatory response and improve insulin resistance as well as other obesity-related disorders. This study investigated the association between omentin-1 expression in human epicardial adipose tissue (EAT) and coronary atherosclerosis.
\end{abstract}

Methods: Serum samples, and paired biopsies from EAT and subcutaneous adipose tissue (SAT), were obtained from patients with and without coronary artery disease (CAD, $n=28$ and NCAD, $n=12$, respectively) during elective cardiac surgery. Coronary angiography was performed to identify CAD presence. Serum omentin-1 and adiponectin levels were measured by ELISA. mRNA expression of omentin-1 and adiponectin was detected in adipose tissue by quantitative realtime PCR, and omentin-1 protein expression was evaluated by immunohistochemistry. Correlation and multivariate linear regression analyses were performed to determine the association between omentin-1 expression and clinical risk factors.

Results: mRNA and protein expression of omentin-1 were higher in EAT than paired SAT in patients with CAD and NCAD. Compared with NCAD patients, CAD patients had lower omentin-1 and adiponectin mRNA levels in EAT and serum levels as well as lower omentin-1 protein levels. Among patients with CAD, omentin-1 expression was lower in EAT surrounding coronary segments with stenosis than those without stenosis, in terms of mRNA and protein, whereas adiponectin mRNA level in EAT did not seem to differ between stenotic and non-stenotic coronary segments in CAD patients. In multivariate linear regression analysis, CAD was an independent predictor of EAT omentin-1 mRNA expression (beta $=-0.57,95 \% \mathrm{Cl}-0.89$ to $-0.24 ; P=0.001$ ) and serum omentin-1 levels (beta $=-0.35,95 \% \mathrm{Cl}$ -0.67 to $-0.03 ; P=0.036)$.

Conclusions: Circulating and EAT-derived omentin-1 levels were reduced in patients with CAD. Omentin-1 expression in patients with CAD was lower in EAT adjacent to coronary stenotic segments than non-stenotic segments.

Keywords: Epicardial adipose tissue, Omentin-1, Atherosclerosis, Coronary artery disease

\section{Background}

Obesity is an important risk factor for cardiometabolic diseases and its prevalence has risen substantially over

\footnotetext{
*Correspondence: zjwang1975@hotmail.com; zyingxinmi@163.com

${ }^{\dagger}$ Zhijian Wang and Yingxin Zhao contributed equally to this work

${ }^{1}$ Beijing Institute of Heart Lung and Blood Vessel Diseases,

Beijing 100029, China

2 Department of Cardiology, Beijing Anzhen Hospital, Capital Medical

University, Beijing 100029, China

Full list of author information is available at the end of the article
}

the last decade [1]. Accumulation of visceral adipose tissue, accompanied by chronic low-grade inflammation, is causally linked to the initiation and progression of multiple obesity-related disorders, including type 2 diabetes mellitus (T2DM), dyslipidemia and atherosclerosis [2, 3]. Epicardial adipose tissue (EAT) has emerged as a novel target for stratification of cardiometabolic risk factors due to its distinctive location, and multifaceted metabolic properties with systemic and local effects. Because EAT is not separated from adjacent myocardium or 
the coronary artery vascular wall by fascia, paracrine or vasocrine interactions are able to occur [4]. In addition, EAT is an active endocrine organ that expresses and secretes numerous adipocytokines $[5,6]$. It has been established that the equilibrium between pro-inflammatory and anti-inflammatory adipocytokine production by EAT is altered in certain pathological conditions [7, 8]. In patients with coronary artery disease (CAD), adiponectin mRNA expression was markedly decreased in EAT, whereas multiple pro-inflammatory adipocytokines mRNA expression, including chemerin, IL-1 $\beta$, IL- 6 and TNF- $\alpha$, were significantly increased [5, 9]. Thus, it is supposed that, adipocytokines secreted by EAT via both paracrine and vasocrine mechanisms may regulate the process of atherosclerosis [4].

Omentin-1, also known as intelectin-1 [10], is abundantly expressed in human visceral adipose tissue and it has been demonstrated to modulate obesity-related cardiometabolic disorders via anti-inflammatory activity [11]. Lower circulating omentin-1 levels associated with various metabolic risk factors, including elevated blood pressure, increased waist circumstance, dyslipidemia and glucose intolerance [12]. In addition, serum omentin-1 levels were negatively associated with carotid plaque and positively correlated with cardiac autonomic neuropathy in patients with T2DM $[13,14]$. Patients with CAD have also been observed to have lower circulating omentin-1 levels compared with those without CAD $[15,16]$. Furthermore, it has been reported that serum omentin levels is a significant predictor of cardiovascular events in patients with suspected CAD and heart failure, as well as in hemodialysis patients with subclinical atherosclerosis [17-19]. Although omentin-1 has been identified as a promising biomarker for obesity-related cardiometabolic diseases, the association between EAT omentin-1 expression and coronary atherosclerosis has not been clarified. To address this, human omentin-1 mRNA and protein expression in EAT was evaluated in patients undergoing elective cardiac surgery with and without established CAD.

\section{Methods}

\section{Subjects}

Between July and November 2015, the study enrolled 40 patients who underwent elective cardiac surgery. Invasive coronary angiography was performed to identify $\mathrm{CAD}$, and patients were divided into the CAD $(\mathrm{n}=28)$ or non-CAD (NCAD; $\mathrm{n}=12$ ) group. CAD group referred to patients with three-vessel disease, left main disease or two-vessel disease with proximal left anterior descending lesion indicated for off-pump coronary artery bypass grafting (CABG). NCAD group referred to patients undergoing open-heart surgery for valvular replacement or atrial septal defect repair and no stenosis was found in coronary artery lumen. Key exclusion criteria were: age $>80$ years, acute myocardial infarction, active chronic inflammation disease, liver or renal failure, and pharmacological glucocorticoid or immunosuppressive therapy.

The study protocol complied with the Declaration of Helsinki and was approved by the ethics committee of Beijing Anzhen Hospital of Capital Medical University. Written informed consent was obtained from each patient before enrollment.

\section{Clinical data collection}

Clinical characteristics, including demographic data, body weight, height, waist circumference, medical history and medication use, were obtained from the hospital records. Body mass index (BMI) was calculated as weight $(\mathrm{kg})$ divided by square of height $\left(\mathrm{m}^{2}\right)$.

\section{Blood sample measurement}

After an overnight fast of $12 \mathrm{~h}$, venous blood samples were collected in sodium heparin Vacutainers (Becton-Dickinson), followed by centrifuging for $15 \mathrm{~min}$ at $3000 \times g$, and storage of serum samples at $-80{ }^{\circ} \mathrm{C}$. Baseline levels of fasting glucose, insulin, glycosylated serum protein, lipid profiles, creatinine, and high-sensitivity C-reactive protein (hsCRP) were measured in the central laboratory of Beijing Anzhen Hospital. Homeostasis model assessment of insulin resistance (HOMA-IR) was used to estimate insulin sensitivity, as calculated by fasting glucose $(\mathrm{mmol} / \mathrm{L}) \times$ fasting insulin $(\mu \mathrm{U} / \mathrm{mL}) / 22.5$.

Concentrations of serum omentin-1 (BioVendor, Czech Republic) and adiponectin (R\&D System, USA) were detected by commercially available enzyme-linked immunosorbent assay (ELISA) kits following the manufacturer's instructions. ELISA intra-assay and inter-assay coefficients of variation were both $<5 \%$. All samples were measured in duplicate.

\section{Adipose tissue acquisition}

Two portions of adipose biopsy were harvested, including EAT near right coronary artery ostium, with or without local coronary stenosis, and subcutaneous adipose tissue (SAT) from the area of chest incision. The tissue samples (average $0.4 \mathrm{~g}$ ) were rinsed with phosphatebuffered saline and then divided into two portions. One portion was stored in liquid nitrogen for RNA isolation and the other was immersed in neutralized formalin for immunohistochemistry.

\section{RNA isolation and quantitative real-time PCR}

Total RNA was extracted from samples using Trizol reagent (Invitrogen, USA). The concentration and purity of extracted RNA were assessed by calculating the ratio of 
optical density at 260 and $280 \mathrm{~nm}$ (OD 260/280), and the integrity of RNA was reflected by the $18 \mathrm{~S}$ and $28 \mathrm{~S}$ ribosomal bands. Two $\mu \mathrm{g}$ of RNA from each biopsy was reverse transcribed with GoScript Reverse Transcription System (Promega, USA) according to the instruction manual. Quantitative real-time PCR analysis was conducted using the CFX Real-Time PCR Detection System (Bio-Rad, USA). Each reaction contained $1 \mu \mathrm{L}$ of resultant cDNA, $0.5 \mu \mathrm{L}$ of each primer $(10 \mu \mathrm{mol} / \mathrm{L}), 8 \mu \mathrm{L}$ of sterile water and $10 \mu \mathrm{L}$ of SYBR Premix Ex TaqTM (TAKARA, Japan). mRNA amplification was performed as follows: $1 \mathrm{~min}$ at $95^{\circ} \mathrm{C}$, then 44 cycles of $5 \mathrm{~s}$ at $95^{\circ} \mathrm{C}$ and $30 \mathrm{~s}$ at $60^{\circ} \mathrm{C}$, followed by $0.5^{\circ} \mathrm{C}$ increments every $5 \mathrm{~s}$ from 55 to $95^{\circ} \mathrm{C}$.

The primers were designed using Primer Premier 6.0 software (Premier, Canada), with the sequences as follows: omentin-1, forward 5'-GACGCCCAGAAAACAG CATC-3', reverse 5'-CGTTGGCTGCTCTCTCGTTA-3'; adiponectin, forward $5^{\prime}$-CTCCTCCTCACTTCCATTCT G-3', reverse $5^{\prime}$-TTTCACCGATGTCTCCCTTA- ${ }^{\prime}$; $\beta$-actin, forward 5'-AGGTCATCACCATTGGCAAT-3', reverse 5'-ACTCGTCATACTCCTGCTTG-3'. Threshold cycle $\left(\mathrm{C}_{\mathrm{T}}\right)$ values were obtained and relative gene expression was calculated using the formula $2^{-\Delta \Delta \text { CT }}$ with SAT fat cell fraction as a reference value.

\section{Immunohistochemistry}

The biopsies were embedded in paraffin and cut into serial sections, and then deparaffinized and rehydrated in descending grades of alcohol, followed by staining with hematoxylin and eosin. Selected slides were incubated in $3 \% \mathrm{H}_{2} \mathrm{O}_{2}$ for $15 \mathrm{~min}$, and then blocked with normal goat serum for $20 \mathrm{~min}$. After removal of excess serum, sections were incubated with the primary antibody (Omentin-1, 1:200 dilution; Abcam, USA) at $4{ }^{\circ} \mathrm{C}$ overnight in a moisture chamber. The sections were then incubated with biotinylated secondary antibodies for $20 \mathrm{~min}$ followed by avidin-biotin reagents for $20 \mathrm{~min}$. Slides were incubated with Diaminobenzidine (DAB) and counterstained for $1 \mathrm{~min}$ with hematoxylin. Light microscope observations and digital images were recorded. Positive staining for omentin-1 was brown. Expression of omentin-1 was semi-quantified by measuring the integrated optical density (IOD) of positively stained tissue via Image-Pro plus software 6.0 (Media Cybernetics, USA). The IOD of each slide was calculated from four separate fields viewed at $\times 200$ magnification.

\section{Statistical analysis}

Continuous data with a normal distribution were expressed as the mean $\pm \mathrm{SD}$ or the median (lower quartile, upper quartile), as appropriate. Mean values were compared by the Student's $t$ test, while median values were compared by the Mann-Whitney $U$ test.
Categorical variables were expressed as percentages and analyzed by a Chi square test. Spearman correlation testing was performed between EAT omentin-1 mRNA levels and EAT adiponectin mRNA levels as well as serum omentin-1 levels. The associations between EAT mRNA omentin-1 levels and serum omentin-1 levels with clinical factors, including CAD and local coronary stenosis, were determined by univariate analysis and multivariate linear regression analysis. All statistical analyses were performed using SPSS 17.0 software (SPSS Inc., Chicago, IL, USA). $P<0.05$ was considered statistically significant.

\section{Results}

\section{Patient characteristics}

The baseline characteristics of patients are presented in Table 1. Patients with CAD were subdivided into stenosis $(\mathrm{n}=15)$ and non-stenosis $(\mathrm{n}=13)$ subgroups, according to the presence or absence of local stenosis near right coronary artery ostium. Compared with the NCAD group, the CAD group were more likely to be overweight or obese, and treated with aspirin, nitrates, statins and $\beta$-blockers. Compared with the stenosis and non-stenosis subgroups, there were no significant differences in age, sex, body weight, diabetes, hypertension, current medications and laboratory examinations, except for serum creatinine levels.

\section{Quantitative real-time PCR analysis}

Because of inadequate adipose tissue, three EAT and two SAT samples were excluded from the CAD group. As shown in Fig. 1a, omentin-1 mRNA levels were higher in EAT than paired SAT samples in the CAD group $(9.86$ vs $0.20, P<0.001)$ and the NCAD group (334.21 vs 0.72 , $P<0.001$ ). Figure $1 \mathrm{~b}$ showed that adiponectin mRNA levels were lower in EAT than paired SAT samples in the CAD group $(0.47 \pm 0.24$ vs $0.81 \pm 0.71, P=0.0287)$, whereas adiponectin mRNA levels did not seem to differ between EAT and paired SAT samples in the NCAD group $(1.03 \pm 0.63$ vs $1.00 \pm 0.60, \mathrm{P}=0.89)$.

EAT omentin-1 and adiponectin mRNA levels were markedly decreased in CAD patients compared with NCAD patients (Fig. 2a. omentin-1 0.02 vs 0.59 , $P<0.001$; Fig. 2b. adiponectin $0.43 \pm 0.22$ vs $1.00 \pm 0.61$, $P<0.001$ ). The stenosis subgroup of CAD patients had lower EAT omentin-1 expression than the non-stenosis subgroup (0.01 vs $0.14, P=0.0127$ ), while non-stenosis CAD patients had lower EAT omentin-1 expression than NCAD patients ( 0.14 vs $0.59, P=0.0392)$. There seemed no significant difference between stenosis and nonstenosis subgroups of CAD patients on EAT adiponectin expression $(0.37 \pm 0.20$ vs $0.51 \pm 0.23, P=0.1005)$, while non-stenosis CAD patients had lower EAT adiponectin expression than NCAD patients $(0.51 \pm 0.23 \mathrm{vs}$ $1.00 \pm 0.61, P=0.0221$ ). 
Table 1 Baseline characteristics of patients in the CAD vs NCAD groups, and the stenosis vs non-stenosis subgroups

\begin{tabular}{|c|c|c|c|c|}
\hline & \multicolumn{3}{|l|}{ CAD } & \multirow[t]{2}{*}{ NCAD (12) } \\
\hline & Stenosis (15) & Non-Stenosis (13) & Total (28) & \\
\hline \multicolumn{5}{|l|}{ Clinical characteristics } \\
\hline Age (years) & $61.73 \pm 4.28$ & $60.08 \pm 3.80$ & $60.96 \pm 4.08$ & $58.50 \pm 5.27$ \\
\hline Male (\%) & $8(53.3)$ & $10(76.9)$ & $18(64.3)$ & $5(47.1)$ \\
\hline $\mathrm{BMI}\left(\mathrm{kg} / \mathrm{m}^{2}\right)$ & $25.48 \pm 3.91$ & $25.93 \pm 2.82$ & $25.69 \pm 3.39$ & $23.09 \pm 2.32^{* \S}$ \\
\hline Waist circumference (cm) & $90.11 \pm 9.68$ & $94.15 \pm 13.31$ & $91.99 \pm 11.47$ & $81.05 \pm 8.94^{* \S}$ \\
\hline Hypertension (\%) & $4(26.7)$ & $3(23.1)$ & $7(25.0)$ & $1(8.3)$ \\
\hline T2DM (\%) & $8(53.3)$ & $8(61.5)$ & $16(57.1)$ & $3(25.0)$ \\
\hline Smoking (\%) & $9(60.0)$ & $9(69.2)$ & $18(64.3)$ & $4(33.3)$ \\
\hline LVEF (\%) & $57.73 \pm 10.31$ & $55.92 \pm 9.51$ & $56.89 \pm 9.80$ & $56.58 \pm 7.50$ \\
\hline \multicolumn{5}{|l|}{ Laboratory examinations } \\
\hline Fasting glucose (mmol/L) & $5.35(4.98,7.30)$ & $5.37(5.02,5.65)$ & $5.36(5.00,6.30)$ & $5.28(4.77,6.04)$ \\
\hline Glycosylated serum protein (\%) & $15.00(14.20,16.80)$ & $14.50(13.80,17.20)$ & $14.65(13.88,17.03)$ & $14.55(14.05,17.75)$ \\
\hline Fasting insulin $(\mu \mathrm{U} / \mathrm{ml})$ & $73.10(13.40,104.50)$ & $9.80(6.05,47.70)$ & $16.35(7.98,80.88)$ & $22.30(11.03,26.20)$ \\
\hline HOMA-IR & $2.49(1.57,6.71)$ & $17.38(3.82,27.92)$ & $4.28(2.07,25.75)$ & $4.27(2.40,8.09)^{\S}$ \\
\hline Triglycerides (mmol/L) & $1.32(0.91,2.04)$ & $1.71(1.15,2.50)$ & $1.52(1.02,2.22)$ & $1.46(1.07,2.59)$ \\
\hline Total cholesterol (mmol/L) & $4.25 \pm 1.27$ & $4.36 \pm 0.88$ & $4.30 \pm 1.09$ & $4.87 \pm 1.32$ \\
\hline $\mathrm{HDL}-\mathrm{C}(\mathrm{mmol} / \mathrm{L})$ & $0.96(0.82,1.18)$ & $0.81(0.73,1.06)$ & $0.88(0.77,1.17)$ & $1.18(0.89,1.73)$ \\
\hline LDL-C (mmol/L) & $2.74 \pm 1.31$ & $2.67 \pm 0.93$ & $2.70 \pm 1.13$ & $3.34 \pm 0.84$ \\
\hline Serum creatinine $(\mu \mathrm{mol} / \mathrm{L})$ & $74.60(65.50,83.10)$ & $82.10(76.15,93.95)^{\#}$ & $78.70(66.98,86.60)$ & $79.90(65.03,84.13)$ \\
\hline Homocysteine $(\mu \mathrm{mol} / \mathrm{L})$ & $15.50(11.00,21.90)$ & $14.20(11.40,22.90)$ & $14.35(11.05,21.90)$ & $14.45(10.93,20.08)$ \\
\hline hsCRP (mg/L) & $1.02(0.38,3.85)$ & $1.01(0.74,2.28)$ & $1.02(0.57,3.00)$ & $2.35(0.67,5.09)$ \\
\hline BNP $(p g / m l)$ & $89.00(43.00,164.00)$ & $85.00(30.50,169.50)$ & $87.00(43.00,157.75)$ & $165.5(87.75,252.25)$ \\
\hline$c T n l(\mu g / L)$ & $0.01(0,0.02)$ & $0.01(0,0.015)$ & $0.01(0,0.02)$ & - \\
\hline \multicolumn{5}{|l|}{ Medications } \\
\hline Aspirin (\%) & $6(40.0)$ & $8(61.5)$ & $14(50.0)$ & $0(0)^{* \S}$ \\
\hline Nitrates (\%) & $13(86.7)$ & $13(100)$ & $26(92.9)$ & $2(16.7)^{* \S}$ \\
\hline ACEI/ARB (\%) & $2(13.3)$ & $2(15.4)$ & $4(14.3)$ & $1(8.3)$ \\
\hline Statins (\%) & $9(60.0)$ & $6(46.2)$ & $15(53.6)$ & $0(0)^{* \S}$ \\
\hline$\beta$-blockers (\%) & $9(60.0)$ & $11(84.6)$ & $20(71.4)$ & $0(0)^{* \S}$ \\
\hline Calcium channel blockers (\%) & $3(20.0)$ & $4(30.8)$ & $7(25.0)$ & $0(0)$ \\
\hline Insulin (\%) & $2(13.3)$ & $2(15.4)$ & $4(14.3)$ & $1(8.3)$ \\
\hline Oral hypoglycemic agents (\%) & $3(20.0)$ & $2(15.4)$ & $5(17.9)$ & $1(8.3)$ \\
\hline
\end{tabular}

Data are shown as mean $\pm S D$, median (lower quartile, upper quartile), or number (\%)

$C A D$ coronary artery disease, NCAD non-coronary artery disease, BMI body mass index, LVEF left ventricular ejection fraction, HOMA-IR homeostasis model assessment of insulin resistance, $H D L-C$ high-density lipoprotein cholesterol, $L D L-C$ low-density lipoprotein cholesterol, $h S C R P$ high-sensitivity C-reactive protein, $B N P$ brain natriuretic peptide, $C T n /$ cardiac troponin I, T2DM type 2 diabetes, $A C E I / A R B$ angiotensin-converting enzyme inhibitor/angiotensin II type 1 receptor blocker

* $P<0.05$, CAD group vs NCAD group

$\S P<0.05$, non-stenosis subgroup vs NCAD group

\# $P<0.05$, stenosis subgroup vs non-stenosis subgroup

\section{Immunohistochemical analysis}

EAT and paired SAT specimens were randomly selected from the CAD group (stenosis subgroup, $\mathrm{n}=9$; nonstenosis subgroup, $n=9)$ and the NCAD group $(n=9)$, respectively. Figure $3 \mathrm{~A}$ shows representative immunostained adipose sections from patients in the CAD group (Fig. 3A-a, b, c) and the NCAD group (Fig. 3A-d, e). In all patients, omentin-1 was highly expressed in EAT, most prominently in stromal vascular cells, but was barely detectable in SAT. As shown in Fig. 3B, omentin-1 protein levels were higher in EAT than paired SAT in both the CAD group $(49,053 \pm 22,145$ vs $28,340 \pm 11,314$, $P=0.0032)$ and NCAD group $(91,290 \pm 27,006$ vs $27,333 \pm 11,648, P<0.001)$. Furthermore, as shown in Fig. 3C, omentin-1 protein levels in EAT were lower in CAD patients than NCAD patients $(49,053 \pm 22,145$ 

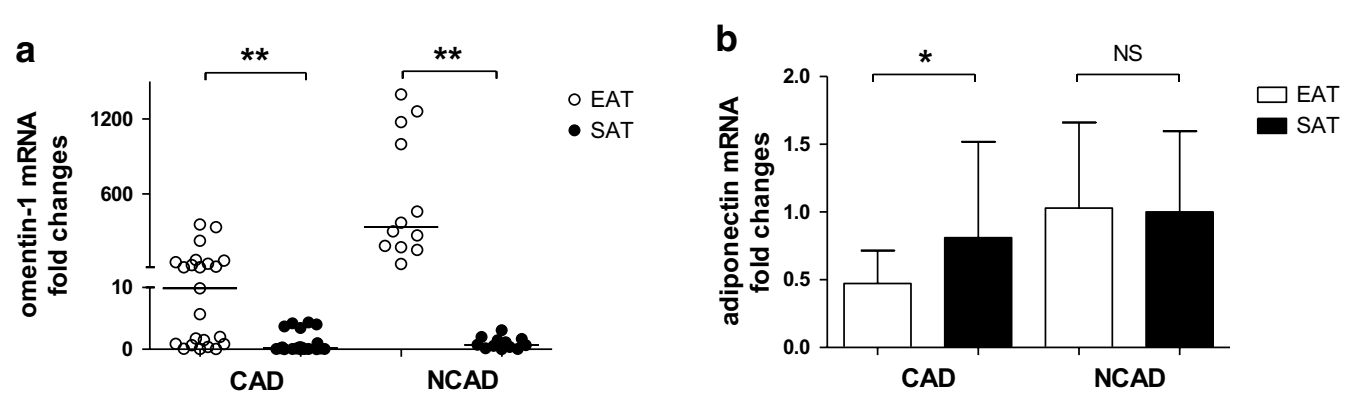

Fig. 1 Quantitative real-time PCR analysis for adipokines in human adipose tissue. Relative omentin-1 (a) and adiponectin (b) mRNA levels in paired EAT and SAT (reference) of the two groups (CAD group, $n=23$; NCAD group, $n=12$ ). ${ }^{*} P<0.05,{ }^{* *} P<0.01$. CAD coronary artery disease, EAT epicardial adipose tissue, NS no significant difference, SAT subcutaneous adipose tissue
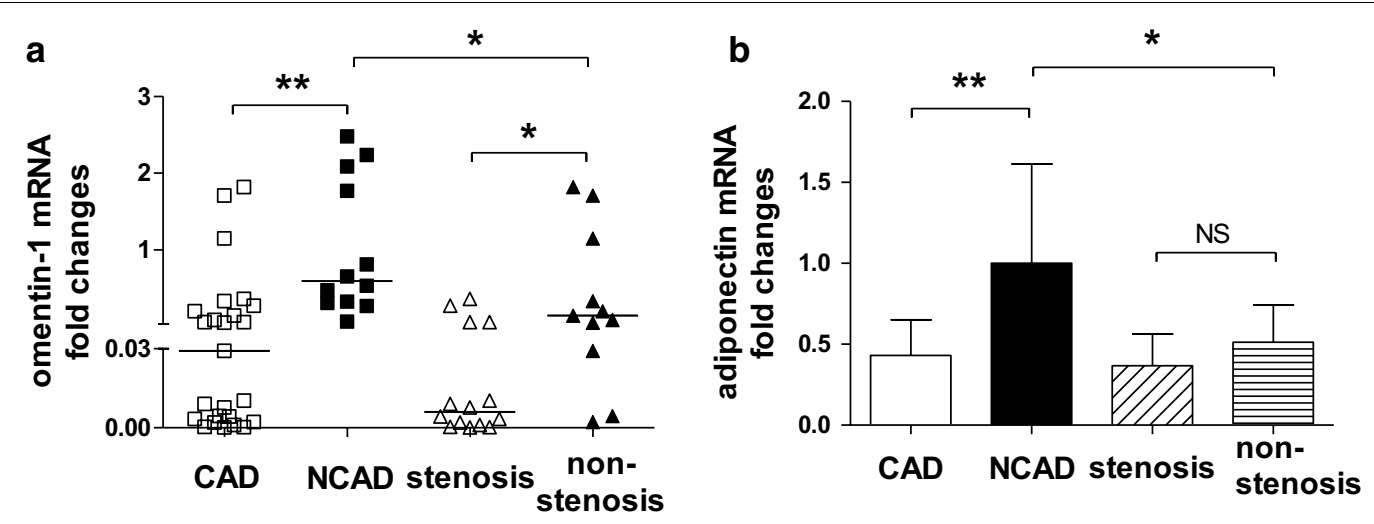

Fig. 2 Quantitative real-time PCR analysis for adipokines in human adipose tissue. Relative omentin-1 (a) and adiponectin (b) mRNA levels in EAT of CAD group (total, $n=25$; stenosis subgroup, $n=14$; non-stenosis subgroup, $n=11$ ) and NCAD group (reference, $n=12$ ). ${ }^{*} P<0.05,{ }^{* *} P<0.01$. CAD coronary artery disease, EAT epicardial adipose tissue, NS no significant difference, SAT subcutaneous adipose tissue

vs $91,290 \pm 27,006, P<0.001)$, while omentin-1 protein expression in EAT was lower in the stenosis subgroup than the non-stenosis subgroup $(36,845 \pm 12,529$ vs $61,262 \pm 23,447, P=0.0141)$. In addition, EATderived omentin-1 protein was lower in the non-stenosis subgroup than the NCAD group $(61,262 \pm 23,447$ vs $91,290 \pm 27,006, P=0.0228)$.

\section{Association of omentin-1 with coronary atherosclerosis and other clinical parameters}

Table 2 showed that in univariate analysis, EAT-derived omentin-1 mRNA was negatively associated with waist circumference (beta $=-0.45,95 \% \mathrm{CI}-0.73$ to -0.14 ), diabetes (beta $=-0.36,95 \% \mathrm{CI}-0.68$ to -0.04 ) and CAD (beta $=-0.66,95 \% \mathrm{CI}-0.90$ to -0.40 ). Multivariate linear regression analysis, including age, sex, waist circumference, diabetes and CAD as covariates, demonstrated that the presence of CAD was independently associated with EAT omentin-1 mRNA levels (beta $=-0.57,95 \% \mathrm{CI}-0.89$ to $-0.24 ; P=0.001$ ).
Among patients with CAD, univariate analysis revealed a negative association between EAT-derived omentin-1 mRNA and local coronary stenosis (beta $=-0.44,95 \%$ CI -0.83 to $-0.05 ; P=0.028)$. EAT omentin- 1 mRNA expression was positively associated with that of adiponectin $(\mathrm{r}=0.39, P=0.018)$, but not with serum omentin-1 levels $(r=0.31, P=0.062)$.

Omentin-1 levels in serum were lower in the CAD group than the NCAD group (373.71 vs $659.39 \mathrm{ng} / \mathrm{mL}$, $P<0.001)$. As shown in Table 2 , in univariate analysis, serum omentin-1 levels were negatively associated with waist circumference (beta $=-0.36,95 \% \mathrm{CI}-0.66$ to -0.05 ), HOMA-IR (beta $=-0.32,95 \% \mathrm{CI}-0.64$ to -0.01 ), hypertension (beta $=-0.32,95 \% \mathrm{CI}-0.63$ to -0.01 ) and CAD (beta $=-0.59,95 \% \mathrm{CI}-0.86$ to -0.33 ). A multivariate linear regression analysis model, including age, sex, waist circumference, HOMO-IR, hypertension, triglycerides and $\mathrm{CAD}$, demonstrated that the presence of CAD was independently associated with serum omenitn-1 levels (beta $=-0.35,95 \% \mathrm{CI}-0.67$ to $-0.03 ; P=0.036$ ). 

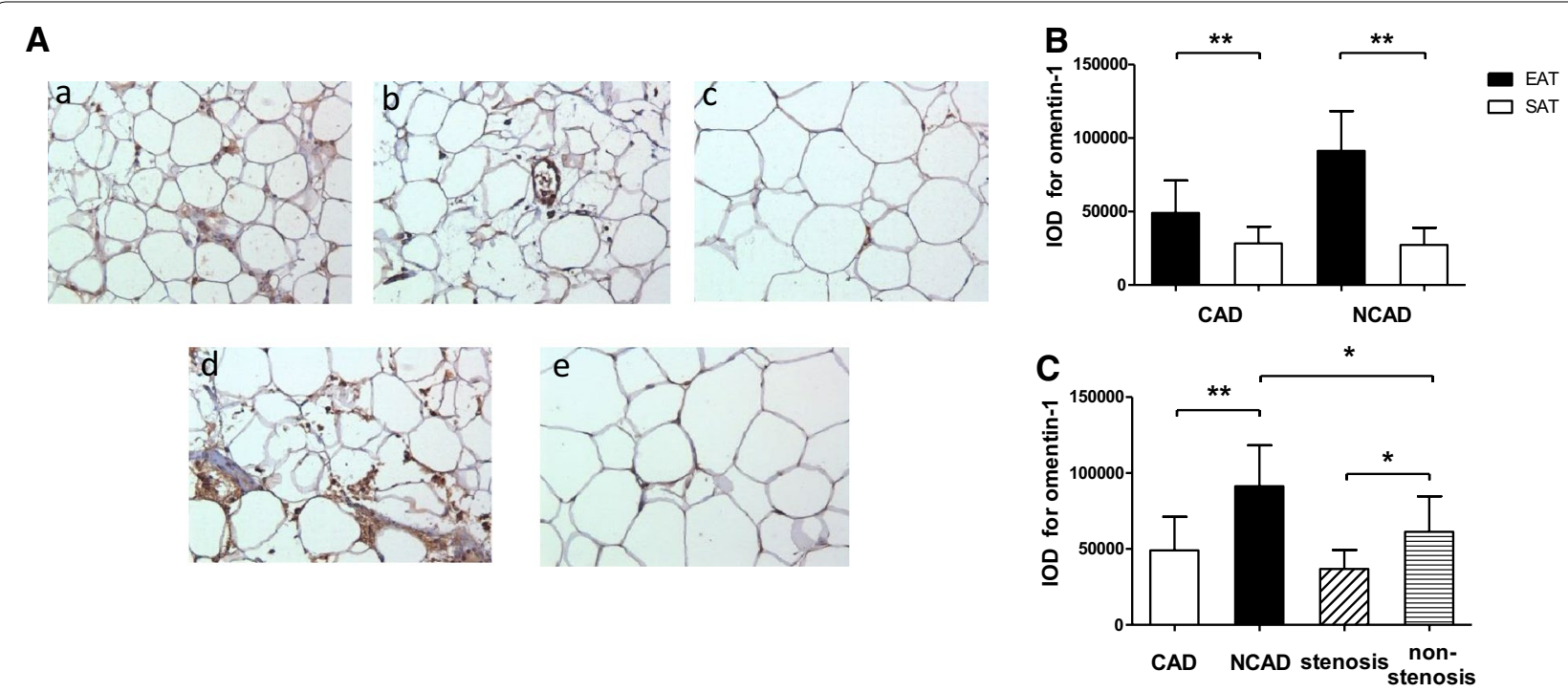

Fig. 3 Immunohistochemical analysis for omentin-1 in human adipose tissue. A representative slides of adipose tissue from patients in the CAD group (Fig. 3A- $a$, EAT of non-stenosis subgroup; $3 \mathbf{A}-b$, EAT of stenosis subgroup; $3 \mathbf{A}-c$, SAT) and the NCAD group (Fig. 3A- $d$, EAT; $3 \mathbf{A}-e$, SAT) (magnified $\times 200$ ). B results of quantitative immunohistochemical analysis for omentin-1 in EAT and SAT of the two groups (CAD group, $n=9 ;$ NCAD group, $n=9$ ). results of quantitative immunohistochemical analysis for omentin-1 in EAT of CAD group (total, $n=18$; stenosis subgroup, $n=9$; non- stenosis subgroup, $n=9)$ and NCAD group $(n=9) .{ }^{*} P<0.05,{ }^{* *} P<0.01$. CAD coronary artery disease, EAT epicardial adipose tissue, SAT subcutaneous adipose tissue, IOD integrated optical density

Table 2 Association between EAT as well as serum levels of omentin-1 and variables using univariate analysis and multivariate linear regression analysis

\begin{tabular}{|c|c|c|c|c|c|c|c|c|c|c|c|c|}
\hline \multirow[t]{3}{*}{ Variables } & \multicolumn{6}{|c|}{ EAT mRNA levels } & \multicolumn{6}{|c|}{ Serum levels } \\
\hline & \multicolumn{3}{|c|}{ Univariate } & \multicolumn{3}{|c|}{$\begin{array}{l}\text { Multivariate } \\
\left(R^{2}=0.419, P<0.001\right)\end{array}$} & \multicolumn{3}{|c|}{ Univariate } & \multicolumn{3}{|c|}{$\begin{array}{l}\text { Multivariate } \\
\left(R^{2}=0.246, P=0.029\right)\end{array}$} \\
\hline & Beta & $95 \% \mathrm{Cl}$ & $P$ value & Beta & $95 \% \mathrm{Cl}$ & $P$ value & Beta & $95 \% \mathrm{Cl}$ & $P$ value & Beta & $95 \% \mathrm{Cl}$ & $P$ value \\
\hline Age & 0.01 & -0.33 to 0.35 & 0.946 & 0.10 & -0.19 to 0.39 & 0.492 & -0.27 & -0.58 to 0.05 & 0.095 & -0.23 & -0.53 to 0.07 & 0.132 \\
\hline Sex & 0.27 & -0.06 to 0.60 & 0.102 & 0.10 & -0.17 to 0.37 & 0.463 & 0.30 & -0.01 to 0.61 & 0.060 & 0.15 & -0.12 to 0.42 & 0.272 \\
\hline WC & -0.45 & -0.73 to -0.14 & 0.005 & -0.12 & -0.42 to 0.19 & 0.445 & -0.36 & -0.66 to -0.05 & 0.024 & -0.16 & -0.47 to 0.15 & 0.308 \\
\hline$C A D$ & -0.66 & -0.90 to -0.40 & $<0.001$ & -0.57 & -0.89 to -0.24 & 0.001 & -0.59 & -0.86 to -0.33 & $<0.001$ & -0.35 & -0.67 to -0.03 & 0.036 \\
\hline $\mathrm{T} 2 \mathrm{DM}$ & -0.36 & -0.68 to -0.04 & 0.029 & -0.11 & -0.39 to 0.17 & 0.438 & -0.29 & -0.60 to 0.03 & 0.072 & & & \\
\hline $\mathrm{TC}$ & -0.11 & -0.24 to 0.47 & 0.520 & & & & 0.36 & 0.05 to 0.66 & 0.024 & 0.23 & -0.04 to 0.50 & 0.093 \\
\hline HTN & -0.26 & -0.57 to 0.07 & 0.127 & & & & -0.32 & -0.63 to -0.01 & 0.046 & -0.02 & -0.35 to -0.31 & 0.887 \\
\hline HOMA-IR & -0.21 & -0.53 to 0.12 & 0.210 & & & & -0.32 & -0.64 to -0.01 & 0.041 & -0.15 & -0.48 to 0.17 & 0.350 \\
\hline
\end{tabular}

Multivariate linear regression model includes age, sex and other variables with $\mathrm{P}<0.05$ in univariate analysis

EAT epicardial adipose tissue, $C l$ confidence interval, WC waist circumference, $C A D$ coronary artery disease, TC triglycerides, HTN hypertension, $T 2 D M$ type 2 diabetes, HOMA-IR homeostasis model assessment of insulin resistance

Adiponectin levels in serum were lower in the CAD group than the NCAD group $(4.57 \pm 0.99$ vs $6.98 \pm 1.11 \mathrm{ng} / \mathrm{mL}, P<0.001)$. As shown in Table 3, multivariate linear regression analysis indicated that the presence of CAD was independently associated with EAT adiponectin mRNA levels (beta $=-0.49,95 \% \mathrm{CI}$ -0.81 to $-0.14 ; P=0.006$ ) and serum adiopnectin levels (beta $=-0.82,95 \% \mathrm{CI}-0.99$ to $-0.66 ; P<0.001$ ).

\section{Discussion}

In this study, we found that in patients with CAD, serum and EAT omentin-1 levels were markedly lower than in patients without CAD, and this inverse association remained after adjusting for well-known risk factors. Furthermore, patients with CAD had lower omentin-1 expression in EAT surrounding stenotic coronary segments compared with normal coronary segments. 
Table 3 Association between EAT as well as serum levels of adiponectin and variables using univariate analysis and multivariate linear regression analysis

\begin{tabular}{|c|c|c|c|c|c|c|c|c|c|c|c|c|}
\hline \multirow[t]{3}{*}{ Variables } & \multicolumn{6}{|c|}{ EAT mRNA levels } & \multicolumn{6}{|c|}{ Serum levels } \\
\hline & \multicolumn{3}{|c|}{ Univariate } & \multicolumn{3}{|c|}{$\begin{array}{l}\text { Multivariate } \\
\left(R^{2}=0.246, P=0.01\right)\end{array}$} & \multicolumn{3}{|c|}{ Univariate } & \multicolumn{3}{|c|}{$\begin{array}{l}\text { Multivariate } \\
\left(R^{2}=0.799, P<0.001\right)\end{array}$} \\
\hline & Beta & $95 \% \mathrm{Cl}$ & $P$ value & Beta & $95 \% \mathrm{Cl}$ & $P$ value & Beta & $95 \% \mathrm{Cl}$ & $P$ value & Beta & $95 \% \mathrm{Cl}$ & $P$ value \\
\hline Age & -0.20 & -0.53 to 0.13 & 0.231 & -0.09 & -0.39 to 0.22 & 0.557 & -0.25 & -0.57 to 0.07 & 0.117 & 0.02 & -0.13 to 0.18 & 0.767 \\
\hline Sex & 0.16 & -0.18 to 0.50 & 0.338 & 0.05 & -0.26 to 0.35 & 0.770 & 0.05 & -0.28 to 0.38 & 0.752 & -0.07 & -0.22 to 0.08 & 0.351 \\
\hline BMI & -0.32 & -0.65 to 0.001 & 0.050 & -0.10 & -0.43 to 0.23 & 0.526 & -0.23 & -0.55 to -0.09 & 0.151 & -0.18 & -0.35 to -0.01 & 0.035 \\
\hline$C A D$ & -0.56 & -0.83 to -0.27 & $<0.001$ & -0.49 & -0.81 to -0.14 & 0.006 & -0.74 & -0.96 to -0.52 & $<0.001$ & -0.82 & -0.99 to -0.66 & $<0.001$ \\
\hline $\mathrm{TC}$ & -0.03 & -0.39 to 0.33 & 0.861 & & & & -0.32 & -0.63 to -0.01 & 0.044 & -0.57 & -0.73 to -0.41 & $<0.001$ \\
\hline HOMA-IR -0.24 & -0.24 & -0.56 to 0.09 & 0.148 & & & & -0.23 & -0.55 to 0.10 & 0.163 & & & \\
\hline HTN & -0.26 & -0.58 to 0.07 & 0.117 & & & & -0.09 & -0.42 to 0.24 & 0.578 & & & \\
\hline Glucose & -0.18 & -0.50 to 0.16 & 0.293 & & & & 0.03 & -0.30 to 0.36 & 0.856 & & & \\
\hline
\end{tabular}

Multivariate linear regression model includes age, sex and other variables with $\mathrm{P}<0.05$ in univariate analysis

EAT epicardial adipose tissue, $C l$ confidence interval, $B M I$ body mass index, CAD coronary artery disease, HOMA-IR homeostasis model assessment of insulin resistance, HTN hypertension, TC triglycerides

Watanabe and co-workers using immunohistochemistry showed that patients with CAD had substantially lower omentin-1 expression in EAT and coronary endothelium [20]. However, the baseline characteristics of CAD and NCAD patients in Watanabe's study were not well matched. Our present study complements and extends prior findings by revealing that omentin- 1 expression in EAT of CAD patients was significantly lower on both the mRNA and protein levels, and these inverse associations between CAD and EAT omentin-1 mRNA as well as protein expression remained after adjusting for well-known risk factors. These findings suggest that omentin-1 derived from EAT associates with CAD, or in another way, the entirely coronary atherosclerosis.

However, whether EAT omentin-1 expression associated with local coronary atherosclerosis has not been clarified. Recent researches indicate that EAT or perivascular adipose tissue has crucial roles in the maintenance of cardiovascular homeostasis and remodeling under physiological or pathological circumstances [21]. It has been established that EAT is a source of adipocytokines, and is closely linked to the initiation and progression of atherosclerosis $[4,5]$. More recently, Benedicte et al. identified 400 common genes involved in extracellular matrix remodeling, thrombosis and inflammation, which were expressed in EAT from the periatrial region, periventricular area and surrounding the pericoronary artery. The authors also showed that omentin was the most highly upregulated gene in EAT compared with SAT [22]. Similarly, we found that omentin-1 mRNA and protein levels were significantly higher in EAT than SAT, regardless of pre-existing CAD. Considering the contiguous anatomic location and microcirculatory connection, it is reasonable to speculate that tissue-specific expression of omentin-1 in EAT closely relates to local coronary atherosclerosis via paracrine and vasocrine mechanisms.

To examined the association between adipocytokine expression in EAT and local coronary atherosclerosis, Verhagen et al. obtained perivascular adipose tissue near to stenotic and non-stenotic coronary artery segments from the same CAD patient undergoing CABG, and he revealed a negative relationship between EAT-derived adipocytokine production and local coronary atherosclerosis [23]. Likewise, we found that among patients with CAD, omentin-1 mRNA and protein levels in EAT surrounding coronary artery stenotic segments were markedly decreased. There was a negative association between EAT-derived omentin-1 mRNA and local coronary stenosis among patients with CAD in a univariate analysis. Therefore, we presume that omentin-1 mRNA expression in EAT was inversely associated with entirely and local coronary atherosclerosis. The former association was further investigated in the comparison of the nonstenosis CAD patients and NCAD patients showing that omentin-1 mRNA and protein levels were lower in the non-stenosis subgroup, which indicated that the negative association between omentin-1 expression in EAT and CAD is independent of local coronary atherosclerosis.

Generally, explanation of the association between EAT derived adipocytokines and coronary atherosclerosis is oversimplified and paracrine effects of EAT may be overestimated. In fact, the delicate equilibrium between proinflammatory and anti-inflammatory adipocytokines is complicated and susceptible to disruption in pathological conditions [7]. Adiponectin, positively associated with omentin-1 in EAT mRNA expression in our study, was 
found to be lower in patients with CAD on EAT mRNA levels and serum levels [5, 24], moreover, we observed that this reverse association between EAT mRNA levels as well as serum levels of adiponectin and CAD still existed adjusting for traditional risk factors. However, adiponectin mRNA expression was not expectantly significantly lower in EAT near to stenotic segments compared with non- stenotic segments in both Verhagen's study and this study. In another small-scale study, adiponectin mRNA levels were not significantly lower in EAT near to coronary segments containing a bare metal stent with heavier atherosclerotic burden when compared with EAT adjacent to segments without a stent [25]. Moreover, secretion of pro-inflammatory adipocytokines (IL-1 $\alpha$, IL-17, IL-18 and IL-23) from EAT adjacent to coronary stenotic segments was markedly reduced in Verhagen's study [23]. Overall, patients with CAD have a stronger pro-inflammatory profile of adipocytokines in EAT than NCAD patients [26], whereas the regulation of adipocytokines in EAT derived from coronary stenotic segments of advanced CAD patients appears to be sophisticated.

Omentin-1 is secreted by visceral fat, and its local concentration in visceral fat may greatly exceed that in the circulation or SAT [27]. In this study, EAT omentin-1 mRNA expression was not positively associated with serum omentin-1 levels. Meanwhile, because omentin-1 circulates in blood, it may improve insulin sensitivity and glucose metabolism in the entire body, which would have an impact on the initiation and progression of obesity-related disorders such as CAD. In the present study, omentin-1 levels in serum were negatively associated with the presence of CAD, even after adjusting for traditional risk factors. This relationship was confirmed in a metaanalysis demonstrating that serum omentin-1 levels were independently and negatively associated with CAD [28]. The present study also showed that serum omentin-1 was negatively correlated with waist circumference and HOMA-IR. These results are in agreement with findings that serum omentin-1 levels are increased in most obesity following bariatric surgery with lower cardiovascular risk [29] and in diabetes after treatment of pioglitazone with improved cardiac diastolic function [30].

The in vivo effect of omentin-1 halted the development of atherosclerosis has been investigated in apolipoprotein E-deficient $\left(\right.$ Apoe $\left.^{-/-}\right)$mice with decreased macrophage infiltration and pro-inflammatory genes expression [20, 31]. In vitro, omentin-1 promoted differentiation of macrophages into the anti-inflammatory M2 phenotype, and suppressed inflammatory responses and foam cell formation [20]. Omentin-1 has been demonstrated to promote vasodilation and survival of endothelial cells through activation of AMPK/eNOS pathways [32], and to alleviate inflammation in endothelial cells via inhibition of TNF- $\alpha$ pathways [33]. In addition, omentin- 1 inhibited monocyte adhesion to smooth muscle cells by reducing VCAM-1 expression through inhibition of p38/JNK signaling [34]. Furthermore, omentin-1 was observed to increase in macrophage-derived foam cells and medial layer VSMCs within advanced coronary plaques and the circulating blood in patients with acute coronary syndrome (ACS) [20], this implies that omentin-1 may exert cardio-protective effects in the acute-phase of ACS, which is of significant importance for targeted therapy.

The limitations of this study should be noted. The characteristics of patients in the CAD and NCAD groups were not balanced, which may confound the association between omentin-1 expression and CAD. Although multivariate regression analysis was performed, the existence of residual confounding variables cannot be excluded. Because of the small sample size, it was not possible to investigate the inverse association between EAT omentin-1 levels and local coronary atherosclerosis in CAD patients by multivariate linear regression analysis. This was a cross-sectional and observational study, therefore, the results should be considered exploratory and hypothesis generating. Conclusions concerning the mechanism and causality between omentin-1 and coronary atherosclerosis cannot be made. Further studies are required to evaluate whether EAT-derived omentin-1 has a direct effect on coronary atherosclerosis.

\section{Conclusions}

This study established that EAT and serum omentin-1 levels were negatively associated with the presence of CAD. However, the inverse relationship between EAT omentin-1 levels and local coronary atherosclerosis requires further elucidation. Future studies focusing on the causality between EAT omentin-1 expression and coronary atherosclerosis as well as its underlying mechanisms are warranted.

\section{Abbreviations}

EAT: epicardial adipose tissue; SAT: subcutaneous adipose tissue; CAD: coronary artery disease; NCAD: non-coronary artery disease; T2DM: type 2 diabetes mellitus; CABG: coronary artery bypass grafting; BMI: body mass index; hsCRP: high-sensitivity C-reactive protein; HOMA-IR: homeostasis model assessment of insulin resistance; ELISA: enzyme-linked immunosorbent assay; $\mathrm{C}_{\mathrm{T}}$ : threshold cycle; DAB: diaminobenzidine; IOD: integrated optical density; Apoe-/-: apolipoprotein E-deficient; ACS: acute coronary syndrome.

\section{Authors' contributions}

YD carried out the molecular genetic studies and serum assessment, and also drafted the manuscript. LC carried out the immunoassays. FJH, YQL, YL, JBY, BH, EJZ, JWZ collected adipose tissue and serum samples. YD performed data collection and reduction, as well as statistical analysis. QWJ and YJZ participated in study design and revised the manuscript critically for important intellectual content. YXZ and ZJW conceived of the study and involved in study design and coordination. All authors read and approved the final manuscript. 


\begin{abstract}
Author details
${ }^{1}$ Beijing Institute of Heart Lung and Blood Vessel Diseases, Beijing 100029 ,

China. ${ }^{2}$ Department of Cardiology, Beijing Anzhen Hospital, Capital Medical University, Beijing 100029, China. ${ }^{3}$ Department of Cardiac Surgery Center, Beijing Anzhen Hospital, Capital Medical University, Beijing 100029, China.
\end{abstract}

\section{Acknowledgements}

This study was supported by National Natural Science Foundation of China (No. 81170265, No. 81270285). We convey thanks to the surgeons Dong Sun, Qiang Wu, Yuan Zhou, Changwei Ren, Jinhua Li and Jingwei Li, for their help in obtaining adipose tissue samples.

\section{Competing interests}

The authors declare that they have no competing interests.

Received: 30 April 2016 Accepted: 7 June 2016

Published online: 28 June 2016

\section{References}

1. Ng M, Fleming T, Robinson M, Thomson B, Graetz N, Margono C, Mullany EC, Biryukov S, Abbafati C, Abera SF, et al. Global, regional, and national prevalence of overweight and obesity in children and adults during 1980-2013: a systematic analysis for the global burden of disease study 2013. Lancet. 2014;384(9945):766-81.

2. Bays HE. Adiposopathy is "sick fat" a cardiovascular disease? J Am Coll Cardiol. 2011;57(25):2461-73.

3. Ouchi N, Parker JL, Lugus JJ, Walsh K. Adipokines in inflammation and metabolic disease. Nat Rev Immunol. 2011;11(2):85-97.

4. lacobellis $\mathrm{G}$. Local and systemic effects of the multifaceted epicardial adipose tissue depot. Nat Rev Endocrinol. 2015;11(6):363-71.

5. Mazurek T, Zhang L, Zalewski A, Mannion JD, Diehl JT, Arafat H, Sarov-Blat L, O'Brien S, Keiper EA, Johnson AG, et al. Human epicardial adipose tissue is a source of inflammatory mediators. Circulation. 2003;108(20):2460-6.

6. Ohashi K, Shibata R, Murohara T, Ouchi N. Role of anti-inflammatory adipokines in obesity-related diseases. TEM. 2014:25(7):348-55.

7. lacobellis G, Corradi D, Sharma AM. Epicardial adipose tissue: anatomic, biomolecular and clinical relationships with the heart. Nat Clin Prac Cardiovasc Med. 2005;2(10):536-43.

8. De Jager SC, Pasterkamp G. Atheroprotective properties of human Omentin-1 in experimental atherosclerosis. Cardiovasc Res. 2016;110(1):1-3.

9. Gao X, Mi S, Zhang F, Gong F, Lai Y, Gao F, Zhang X, Wang L, Tao H. Association of chemerin mRNA expression in human epicardial adipose tissue with coronary atherosclerosis. Cardiovasc Diabetol. 2011;10:87.

10. Komiya T, Tanigawa Y, Hirohashi S. Cloning of the novel gene intelectin, which is expressed in intestinal paneth cells in mice. Biochem Biophys Res Commun. 1998;251(3):759-62.

11. Tan $Y L$, Zheng $X L$, Tang CK. The protective functions of omentin in cardiovascular diseases. Clin Chim Acta. 2015;448:98-106.

12. Shibata R, Ouchi N, Takahashi R, Terakura Y, Ohashi K, Ikeda N, Higuchi A, Terasaki H, Kihara S, Murohara T. Omentin as a novel biomarker of metabolic risk factors. Diabetol Metab Syndr. 2012;4(1):37.

13. Yoo HJ, Hwang SY, Hong HC, Choi HY, Yang SJ, Seo JA, Kim SG, Kim NH, Choi KM, Choi DS, et al. Association of circulating omentin-1 level with arterial stiffness and carotid plaque in type 2 diabetes. Cardiovasc Diabetol. 2011;10:103.

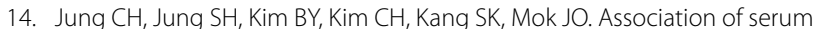
omentin levels with cardiac autonomic neuropathy in patients with type 2 diabetes mellitus: a hospital-based study. Cardiovasc Diabetol. 2015;14:140.

15. Shibata R, Ouchi N, Kikuchi R, Takahashi R, Takeshita K, Kataoka Y, Ohashi K, Ikeda N, Kihara S, Murohara T. Circulating omentin is associated with coronary artery disease in men. Atherosclerosis. 2011;219(2):811-4.

16. Stejskal D, Vaclavik J, Smekal A, Svobodova G, Richterova R, Svestak M. Omentin-1 levels in patients with premature coronary artery disease, metabolic syndrome and healthy controls. Short communication. Biomedical papers of the Medical Faculty of the University Palacky, Olomouc, Czechoslovakia 2016
17. Saely CH, Leiherer A, Muendlein A, Vonbank A, Rein P, Geiger K, Malin C, Drexel $\mathrm{H}$. High plasma omentin predicts cardiovascular events independently from the presence and extent of angiographically determined atherosclerosis. Atherosclerosis. 2015;244:38-43.

18. Kocijancic M, Cubranic Z, Vujicic B, Racki S, Dvornik S, Zaputovic L. Soluble intracellular adhesion molecule-1 and omentin-1 as potential biomarkers of subclinical atherosclerosis in hemodialysis patients. Int Urol Nephrol. 2016.

19. Narumi T, Watanabe T, Kadowaki S, Kinoshita D, Yokoyama M, Honda Y, Otaki Y, Nishiyama S, Takahashi H, Arimoto T, et al. Impact of serum omentin-1 levels on cardiac prognosis in patients with heart failure. Cardiovasc Diabetol. 2014;13:84.

20. Watanabe K, Watanabe R, Konii H, Shirai R, Sato K, Matsuyama TA, Ishibashi-Ueda H, Koba S, Kobayashi Y, Hirano T, et al. Counteractive effects of omentin-1 against atherogenesisdagger. Cardiovasc Res. 2016;110(1):118-28.

21. Takaoka M, Nagata D, Kihara S, Shimomura I, Kimura Y, Tabata Y, Saito Y, Nagai R, Sata M. Periadventitial adipose tissue plays a critical role in vascular remodeling. Circ Res. 2009;105(9):906-11.

22. Gaborit B, Venteclef N, Ancel P, Pelloux V, Gariboldi V, Leprince P, Amour J, Hatem SN, Jouve E, Dutour A, et al. Human epicardial adipose tissue has a specific transcriptomic signature depending on its anatomical peri-atrial, peri-ventricular, or peri-coronary location. Cardiovasc Res. 2015;108(1):62-73.

23. Verhagen SN, Buijsrogge MP, Vink A, van Herwerden LA, van der Graaf Y, Visseren FL. Secretion of adipocytokines by perivascular adipose tissue near stenotic and non-stenotic coronary artery segments in patients undergoing CABG. Atherosclerosis. 2014;233(1):242-7.

24. Ji Q, Lin Y, Liang Z, Yu K, Liu Y, Fang Z, Liu L, Shi Y, Zeng Q, Chang C, et al. Chemerin is a novel biomarker of acute coronary syndrome but not of stable angina pectoris. Cardiovasc Diabetol. 2014;13:145.

25. Spener RF, Breda JR, Pires AC, Pinhal MA, Souto RP. Adiponectin expression in epicardial adipose tissue after percutaneous coronary intervention with bare-metal stent. Revista Brasileira de Cirurgia Cardiovasc. 2011;26(3):427-32.

26. Cheng KH, Chu CS, Lee KT, Lin TH, Hsieh CC, Chiu CC, Voon WC, Sheu SH, Lai WT. Adipocytokines and proinflammatory mediators from abdominal and epicardial adipose tissue in patients with coronary artery disease. Int J Obes (2005). 2008;32(2):268-74.

27. Yang R-Z, Lee M-J, Hu H, Pray J, Wu H-B, Hansen BC, Shuldiner AR, Fried SK, MCLenithan JC, Gong D-W. Identification of omentin as a novel depotspecific adipokine in human adipose tissue: possible role in modulating insulin action. Am J Physiol Endocrinol Metab. 2006;290(6):E1253-61.

28. Agasthi P, Aloor S, Axiyan M, Onwuanyi A. Abstract 548: association between serum omentin-1 level and coronary artery disease: a metaanalysis. Arterioscler Thromb Vasc Biol. 2015;35(Suppl 1):A548.

29. Lapointe M, Poirier P, Martin J, Bastien M, Auclair A, Cianflone K. Omentin changes following bariatric surgery and predictive links with biomarkers for risk of cardiovascular disease. Cardiovasc Diabetol. 2014;13:124.

30. Greulich S, Chen WJ, Maxhera B, Rijzewijk LJ, van der Meer RW, Jonker JT, Mueller H, de Wiza DH, Floerke RR, Smiris K, et al. Cardioprotective properties of omentin-1 in type 2 diabetes: evidence from clinical and in vitro studies. PLoS ONE. 2013;8(3):e59697.

31. Hiramatsu-Ito M, Shibata R, Ohashi K, Kambara T, Yuasa D, Joki Y, Hayakawa S, Ogawa H, Murohara T, Ouchi N. Abstract 11475: overexpression of human omentin in a fat-specific manner attenuates atherosclerotic lesion formation in apoe-deficient mice. Circulation. 2014;130(Suppl 2):A11475.

32. Maruyama S, Shibata R, Kikuchi R, Izumiya Y, Rokutanda T, Araki S, Kataoka Y, Ohashi K, Daida H, Kihara S, et al. Fat-derived factor omentin stimulates endothelial cell function and ischemia-induced revascularization via endothelial nitric oxide synthase-dependent mechanism. J Biol Chem. 2012;287(1):408-17.

33. Yamawaki H, Kuramoto J, Kameshima S, Usui T, Okada M, Hara Y. Omentin, a novel adipocytokine inhibits TNF-induced vascular inflammation in human endothelial cells. Biochemd Biophys Res Commun. 2011:408(2):339-43.

34. Kazama K, Usui T, Okada M, Hara Y, Yamawaki H. Omentin plays an anti-inflammatory role through inhibition of TNF-alpha-induced superoxide production in vascular smooth muscle cells. Eur J Pharmacol. 2012;686(1-3):116-23. 